\title{
OPEN Theoretical insight on the treatment of $\beta$-hexachlorocyclohexane waste through alkaline dehydrochlorination
}

Alicia Bescós ${ }^{1}$, Clara I. Herrerías ${ }^{1}$, Zoel Hormigón ${ }^{1,2}$, José Antonio Mayoral ${ }^{1}$ \& Luis Salvatella ${ }^{1 \bowtie}$

The occurrence of 4.8-7.2 million tons of hexachlorocyclohexane $(\mathrm{HCH})$ isomers stocked in dumpsites around the world constitutes a huge environmental and economical challenge because of their toxicity and persistence. Alkaline treatment of an $\mathrm{HCH}$ mixture in a dehydrochlorination reaction is hampered by the low reactivity of the $\beta-\mathrm{HCH}$ isomer $(\mathrm{HCl}$ elimination unavoidably occurring through syn $\mathrm{H}-\mathrm{C}-\mathrm{C}-\mathrm{Cl}$ arrangements). More intriguingly, the preferential formation of 1,2,4-trichlorobenzene in the $\beta-\mathrm{HCH}$ dehydrochlorination reaction (despite the larger thermodynamical stability of the 1,3,5-isomer) has remained unexplained up to now, though several kinetic studies had been reported. In this paper, we firstly show a detailed Density Functional study on all paths for the hydroxide anion-induced elimination of $\beta-\mathrm{HCH}$ through a three-stage reaction mechanism (involving two types of reaction intermediates). We have now demonstrated that the first reaction intermediate can follow several alternative paths, the preferred route involving abstraction of the most acidic allylic hydrogen which leads to a second reaction intermediate yielding only 1,2,4-trichlorobenzene as the final reaction product. Our theoretical results allow explaining the available experimental data on the $\beta-\mathrm{HCH}$ dehydrochlorination reaction (rate-determining step, regioselectivity, instability of some reaction intermediates).

The occurrence of many uncontrolled stockpiles containing large quantities of Persistent Organic Pollutants (POPs) constitutes a major environmental, economical challenge to be solved ${ }^{1,2}$. Interestingly, most of such waste is derived from the 1,2,3,4,5,6-hexachlorocyclohexane $(\mathrm{HCH})$ production by means of benzene photochlorination. Between 4.8 and 7.2 million tons of $\mathrm{HCH}$ waste are estimated to have been produced and stocked around the world ${ }^{3}$.

The raw product from benzene photochlorination is mostly composed of a mixture of $\mathrm{HCH}$ diastereomers named by Greek letters $(55-80 \% \alpha, 5-14 \% \beta, 8-15 \% \gamma, 2-16 \% \delta, 3-5 \% \varepsilon \text {, see Fig. } 1)^{4}$. In the 1940 s and 50 s, the technical $\mathrm{HCH}$ mixture as a whole was commercialized as an insecticide. Since insecticidal properties are indeed only due to $\gamma-\mathrm{HCH}$ (lindane), the industrial process was subsequently modified to extract that stereoisomer, whereas the remaining isomers (as well as non-extracted $\gamma-\mathrm{HCH}$ ) were deposed in dumpsites close to the production plants, which have become serious pollution foci ${ }^{4}$.

Despite the apparent similitude between $\mathrm{HCH}$ isomers, $\beta-\mathrm{HCH}$ shows a particular chemical behavior. Because of the all-trans arrangement of chlorine atoms in $\beta-\mathrm{HCH}$ (all $\mathrm{H}-\mathrm{C}-\mathrm{C}-\mathrm{Cl}$ sequences showing cis dispositions), elimination is significantly hampered. Thus, Cristol et al. showed that $\beta-\mathrm{HCH}$ reacts with hydroxide ion in an ethanol/water mixture at $30^{\circ} \mathrm{C}$ much more slowly than other isomers (from 7000 to 24,000 times) ${ }^{5}$.

Significant environmental differences between $\mathrm{HCH}$ isomers can accordingly be found ${ }^{6}$. Thus, $\alpha-\mathrm{HCH}$ and $\gamma$-HCH are slowly hydrolyzed in seawater (hydrolytic half-lives are 26 and $42 \mathrm{a}$, respectively) ${ }^{7}$ whereas a negligible reactivity of $\beta-\mathrm{HCH}$ can be inferred from Cristol data (half-life $=38-96 \mathrm{Ga}$ ). High persistence of $\beta-\mathrm{HCH}$ is also found for bacterial degradation since LinA-type enzymes (using an E2 path) ${ }^{8}$ degrade $\alpha-, \gamma$ - and $\delta$-HCH, but

${ }^{1}$ Instituto de Síntesis Química y Catálisis Homogénea (ISOCH), CSIC-Universidad de Zaragoza, Pedro Cerbuna 12, 50009 Zaragoza, Spain. ${ }^{2}$ Present address: Instituto de Tecnología Química (ITQ-CSIC), Avenida de los Naranjos s/n, 46022 Valencia, Spain. ${ }^{\circledR}$ email: Isalvate@unizar.es 
<smiles>ClC1C(Cl)[C@H](Cl)[C@@H](Cl)[C@@H](Cl)[C@H]1Cl</smiles><smiles>ClC1[C@H]([Hg])[C@@H](Cl)[C@@H](Cl)[C@@H](Cl)[C@H]1Cl</smiles><smiles>ClC1C(Cl)[C@H](Cl)[C@@H](Cl)C(Cl)[C@H]1Cl</smiles><smiles>ClC1[C@H](Cl)[C@H](Cl)[C@H](Cl)[C@H](Cl)[C@H]1Cl</smiles><smiles>ClC1C(Cl)[C@H](Cl)[C@@H](Cl)[C@@H](Cl)[C@H]1Cl</smiles>

Figure 1. Major $\mathrm{HCH}$ diastereomers.

not the $\beta$ isomer'. As a consequence of the scarcity of natural degradation mechanisms, $\beta-\mathrm{HCH}$ is becoming the predominant isomer in the environment ${ }^{10}$ as observed in the Baltic Sea water ${ }^{11}$ and human fatty tissues ${ }^{12}$.

Because of their suspected carcinogenic, persistent, bioaccumulative, and endocrine-disrupting properties, $\alpha-, \beta-$, and $\gamma-\mathrm{HCH}$ isomers were included in Annex A of the Stockholm Convention on Persistent Organic Pollutants ${ }^{13}$ thus compelling the signing countries to eliminate releases of such compounds. Evidently, the best strategy to avoid accidental $\mathrm{HCH}$ emissions should include the transformation of $\mathrm{HCH}$ stockpiles into innocuous materials ${ }^{3}$.

Inexpensive safe treatment of large quantities of $\mathrm{HCH}$ waste may be envisaged through dehydrochlorination reaction with sodium hydroxide. However, obtaining quantitative yields in the alkaline treatment of an $\mathrm{HCH}$ mixture is seriously hampered by the low reactivity of the $\beta$-isomer. Reaction mixtures including significant concentrations of $\beta-\mathrm{HCH}$ should not be acceptable.

As a further challenge, the alkali elimination of $\mathrm{HCH}$ isomers (including $\beta-\mathrm{HCH}$ ) preferentially leads to $1,2,4$-trichlorobenzen $e^{14}$ despite the larger stability of $1,3,5$-isomer ${ }^{15}$. No satisfactory explanation has been given up to now to such a paradoxical result.

In this work, we study the complete mechanism for the $\beta-\mathrm{HCH}+$ hydroxide anion reaction using DensityFunctional calculations. We hope that a better mechanistic insight on that process can help to a rational design of $\mathrm{HCH}$ waste treatment.

\section{Results and discussion}

Elimination pathways. The $\beta$-HCH dehydrochlorination reaction takes place through three stages (Fig. 2). The first reaction stage corresponds to $\beta$ - $\mathrm{HCH}$ elimination yielding rel-(3R,4S,5R,6S)-1,3,4,5,6-pentachlorocyclohexene (1). The Gibbs free energy of activation (starting from the $\beta-\mathrm{HCH}+\mathrm{HO}^{-}$pre-reactive complex) for the first stage was firstly studied by using different theoretical levels in gas phase and two continuum models. Results on the activation barrier (see Table S1) are consistent with well-known trends for theoretical levels (exaggeration by $\mathrm{HF}^{16}$, underestimation for $\mathrm{BLYP}^{17}$, similar results for B3LYP and $\mathrm{M} 06-2 \mathrm{X}^{18}$ ) and continuum models (lower activation barriers in gas phase ${ }^{19}$, close results for IEFPCM and CPCM models ${ }^{20}$ ). As a consequence, $\mathrm{CPCM}$ (water)/M06-2X/6-311++G(d,p) calculations are only considered along the paper.

The activation barrier for the first reaction stage $\left(9.3 \mathrm{~kJ} \mathrm{~mol}^{-1}\right)$ is much lower than the experimental value for the $\beta-\mathrm{HCH}+$ sodium hydroxide reaction in ethanol at $30^{\circ} \mathrm{C}(129.8 \mathrm{~kJ} / \mathrm{mol})^{21}$, consistently with the overestimated reactivity of anions by using continuum solvent models ${ }^{22}$. Nevertheless, the occurrence of a positive activation barrier for the first reaction stage for $\beta-\mathrm{HCH}$ (in contrast with the lack of calculated TSs for other isomers) is consistent with the well-known aversion for the syn $\mathrm{H}-\mathrm{C}-\mathrm{C}-\mathrm{Cl}$ arrangement in elimination reactions ${ }^{14}$.

In the second reaction stage, eight dehydrochlorination reaction paths starting from $\mathbf{1}$ (three of them leading to 5 as a common product) to yield tetrachlorocyclohexadienes 2-7 can be envisaged. Both 1,2 (involving two contiguous $\mathrm{sp}^{3}$ carbons) and 1,4 (involving both $\mathrm{sp}^{3}$ allylic carbons) regiochemistries are possible.

Pathways for dehydrochlorination of $\mathbf{1}$ leading to tetrachlorocyclohexadienes 2-6 showed positive activation Gibbs free energies. Routes involving the removal of allylic hydrogens from C3 and C6 $\left(4.2-9.6 \mathrm{~kJ} \mathrm{~mol}^{-1}\right)$ are clearly preferred over those implying non-allylic atoms $\mathrm{C} 4$ and $\mathrm{C} 5\left(33.4-34.8 \mathrm{~kJ} \mathrm{~mol}^{-1}\right)$, in agreement with the relative acidity of allylic hydrogens. When routes leading to conjugated tetrachlorocyclohexadienes are compared, a preference for the formation of $\mathbf{5}$ (involving allylic proton removal) relative to $\mathbf{2}$ (implying non-allylic hydrogen abstraction) by a 200,000:1 ratio (according to calculated relative rate constant $\mathrm{s}^{23}$ ) is found.

All attempts to locate transition states for the transformations of $\mathbf{1}$ into non-conjugated tetrachlorocyclohexadienes ( 3 and $\mathbf{4}$ ) yielded instead structures leading to the favored conjugated isomers.

No TS could be located for the $1 \rightarrow 7$ transformation using the M06-2X or the HF level (typically overestimating activation barriers ${ }^{16}$ ) since a monotonic energy descent for the $\mathbf{1}+\mathrm{HO}^{-}$approximation leading to 7 is found instead. A strong preference for the formation of 7 as a key intermediate in the $\beta$ - $\mathrm{HCH}$ elimination, even larger than that corresponding for the formation of the other conjugated tetrachlorocyclohexadienes, can thus be inferred.

To ascertain the source of the strong preference of $\mathbf{1}$ for the formation of 7 , calculations were carried out on 1,3- and 1,2-dichlorocyclohex-2-en-1-yl carbanions (see Fig. 3), lacking additional $\mathrm{C}_{\mathrm{sp}}{ }^{3}$-bound chlorines (thus 


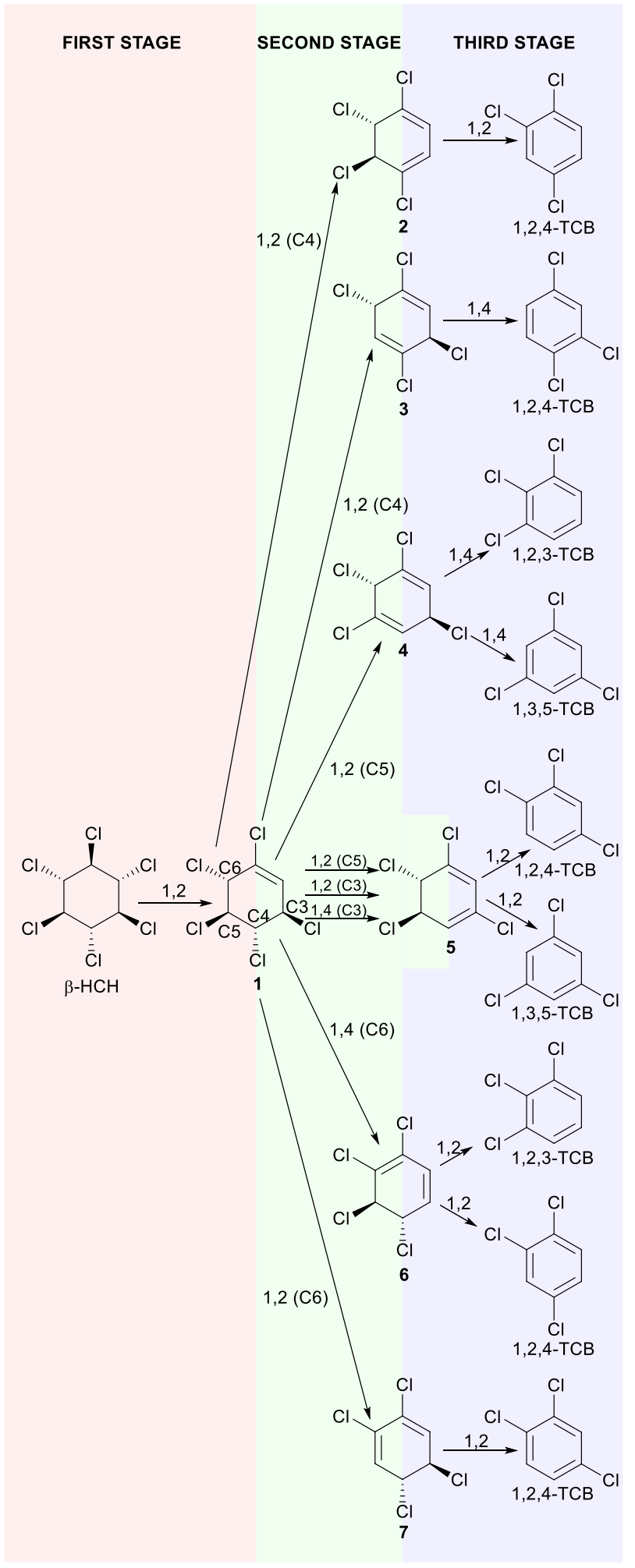

Figure 2. $\beta-\mathrm{HCH}$ dehydrochlorination reaction pathways indicating the regiochemistry $(1,2 \mathrm{vs} .1,4)$ and the carbon undergoing deprotonation (in parentheses, if necessary) of every elimination step.

avoiding the spontaneous chloride anion leave). Interestingly, non-planar $\pi$-allyl structures were found in both cases, similarly to 1-fluoro or 1-hydroxy substituted allyl anions through HF/6-31+G(d) calculations ${ }^{24}$. Such a geometrical feature can be attributed to the preference for the pyramidal geometry of the carbanionic carbon 

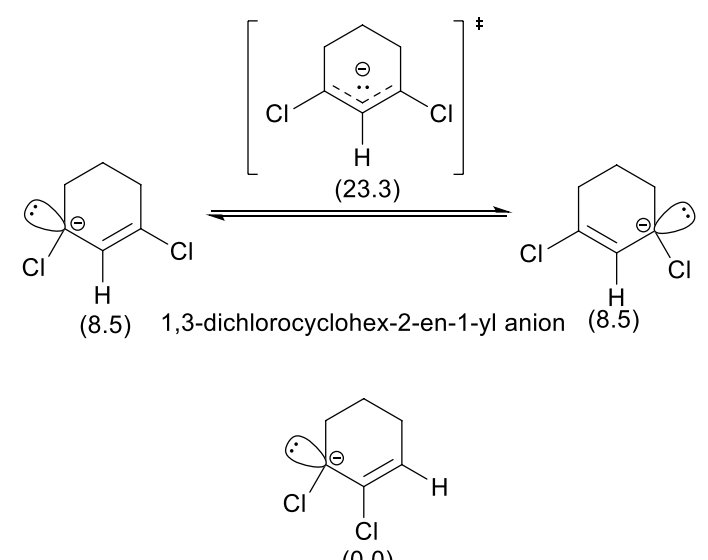

$(0.0)$

1,2-dichlorocyclohex-2-en-1-yl anion

Figure 3. 1,3- and 1,2-Dichlorocyclohex-2-en-1-yl carbanions. Calculated relative Gibbs free energies (kJ $\mathrm{mol}^{-1}$ ) are shown in parentheses.

(lone pair showing a $22.13 \% \mathrm{~s}+77.19 \%$ p hybridization, according to NBO calculations) as a consequence of the $\mathrm{C}-\mathrm{Cl}$ bond polarity ${ }^{25}$, analogously to the strong predilection for pyramidal geometry in $\mathrm{NF}_{3}{ }^{26}$.

For 1,3-dichlorocyclohex-2-en-1-yl anion, two enantiomeric minima can interconvert through a delocalized TS, thus indicating a stabilization through localization $\left(16.5 \mathrm{~kJ} \mathrm{~mol}^{-1}\right.$ in electronic energy; $14.8 \mathrm{~kJ} \mathrm{~mol}^{-1}$ in Gibbs free energy) in contrast with the localization destabilization of the non-substituted allyl anion ${ }^{27}$. An energy minimum was found for the localized 1,2-dichlorocyclohex-2-en-1-yl carbanion, but not for the alternative localized allylic system (2,3-dichlorocyclohex-2-en-1-yl anion).

Calculations show larger stability for 1,2-dichlorocyclohex-2-en-1-yl carbanion relative to the 1,3-isomeric anion $\left(8.0 \mathrm{~kJ} \mathrm{~mol}^{-1}\right.$ in electronic energy; $8.5 \mathrm{~kJ} \mathrm{~mol}^{-1}$ in Gibbs free energy). These results show that the stabilization of an allylic carbanion by a chlorine substituent is larger on the central position than that on the extremal site, consistently with the larger gas phase acidity of 2 -chloropropene ${ }^{28}$ relative to 1-chloropropene ${ }^{24}$.

Calculations show larger stability for 1,2-dichlorocyclohex-2-en-1-yl carbanion relative to the 1,3-isomeric anion $\left(8.0 \mathrm{~kJ} \mathrm{~mol}^{-1}\right.$ in electronic energy; $8.5 \mathrm{~kJ} \mathrm{~mol}^{-1}$ in Gibbs free energy). These results show that a chlorine in the central position increases the stability of the allylic carbanion more than a chlorine in the extremal site, which is consistent with the fact that 2-chloropropene is more acidic than 1-chloropropene in gas phase ${ }^{24}$.

In other words, chloroalkenes show a preference for proton removal from the $\mathrm{CH}$ group next to the chlorinebearing vinylic carbon rather than that contiguous to hydrogen-bearing vinylic carbon.

The extension of such a conclusion to reaction intermediate $\mathbf{1}$ allows understanding the preferential deprotonation from C6 rather than proton removal from C3. Although both 1,2- and 1,4-elimination regiochemistries (leading, respectively, to 7 and 6) can be envisaged, a preference for the formation of 7 in the second stage is finally found.

The third reaction stage corresponds to the elimination of tetrachlorocyclohexadienes 2-7 yielding trichlorobenzene (TCB) isomers. Two alternative dehydrochlorination paths (or one, if equivalent) are possible starting from every tetrachlorocyclohexadiene (involving the chloride anion leave from each carbon) leading to two (or one) trichlorobenzene(s). Very low or negative activation Gibbs free energies (between $-3.2 \mathrm{~kJ} \mathrm{~mol}^{-1}$ and $+3.8 \mathrm{~kJ} \mathrm{~mol}^{-1}$ ) are found for the third stage involving the elimination of intermediates 2-7 (monotonic energy descents were indeed found for both transformations $3 \rightarrow 1,2,4$-TCB and $4 \rightarrow 1,3,5$-TCB). Such results can be attributed to the aromaticity emergence as the driving force of the third stage. The high decomposition rate of tetrachlorocyclohexadienes allows explaining the composition of Dense Nonaqueous Phase Liquid (DNAPL) formed in $\mathrm{HCH}$ dumpsites, typically rich in hexachlorocyclohexanes, pentachlorocyclohexenes, and trichlorobenzenes, but lacking tetrachlorocyclohexadienes ${ }^{29}$.

The preferred reaction pathway involves the sequence $\beta-\mathrm{HCH} \rightarrow \mathbf{1} \rightarrow \mathbf{7} \rightarrow 1,2,4$-TCB where the first stage corresponds to the rate-limiting step, as typically found in kinetic studies ${ }^{5,14}$. A more detailed description of such a preferred path is gathered below.

Preferred reaction path. Calculated reaction intermedia and TSs involved in the most favored pathway for the complete elimination reaction of $\beta-\mathrm{HCH}$ is shown in Fig. 4. A preference for the all-equatorial conformation is found for $\beta-\mathrm{HCH}$.

The reaction of $\beta-\mathrm{HCH}$ with hydroxide anion leads to a very asynchronous TS for the first reaction stage, the $\mathrm{C}-\mathrm{H}$ bond being essentially broken $(1.896 \AA)$, whereas the $\mathrm{C}-\mathrm{Cl}$ bond is almost intact (1.911 $\AA$ ). High asynchronicity for syn E2 TSs (in comparison with anti structures) has also been reported in theoretical studies on reactions of fluoride anion with fluoroethane ${ }^{30}$ and iodoethane ${ }^{31}$. The high asynchronicity of a syn 1,2-elimination TSs (involving a very advanced proton removal and a very incipient chloride anion leave) allows explaining the strong influence of proton acidity on activation barriers. A chair conformation is adopted by the cyclohexane ring in the TS for the first elimination stage, in contrast with Hine's proposal on a boat form ${ }^{21}$. On the other 

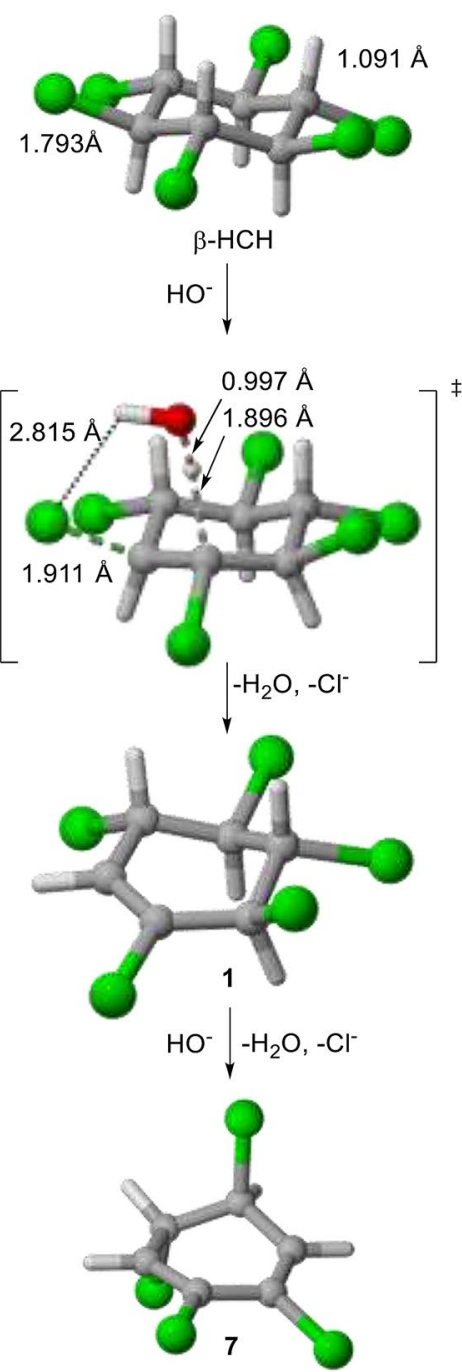

$\mathrm{HO}^{-}$
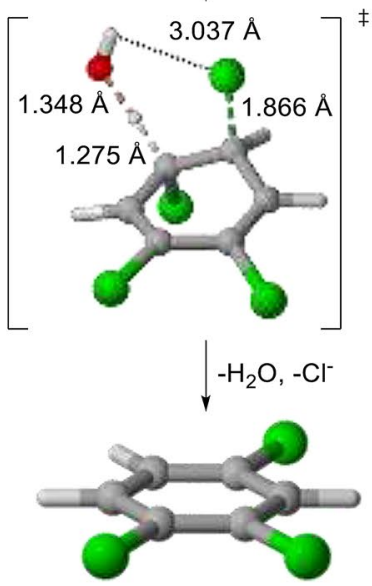

$1,2,4-\mathrm{TCB}$

Figure 4. Preferred reaction path for the complete $\beta-\mathrm{HCH}+$ hydroxide anion elimination. Three-dimensional structures were generated using CYLView ${ }^{44}$. 
hand, the water molecule (formed by proton removal by hydroxide anion) is bound to the leaving chloride anion through electrostatic interactions $(2.815 \AA)$.

Reaction intermediate $\mathbf{1}$ is obtained in the first reaction stage. Such species can undergo a new reaction with hydroxide anion through different paths, though the preferred route yields reaction intermediate 7 . Instead, intermediate 7 can only undergo a new $\mathrm{HCl}$ elimination through two equivalent paths.

Comparison between TSs for $\beta-\mathrm{HCH} \rightarrow \mathbf{1}$ and $7 \rightarrow 1,2,4$-TCB transformations shows a more reactant-like geometry for the latter (breaking C...H bond length: $1.896 \AA$ vs. $1.275 \AA$, respectively), in agreement with the Hammond postulate because of more negative reaction energy due to the trichlobenzene aromaticity emergence. A very incipient water-assistance for the chloride anion $(\mathrm{Cl} \cdots \mathrm{H}$ distance $=3.037 \AA)$ is also found.

The preferential formation of $1,2,4-\mathrm{TCB}$ as the major reaction product has been usually observed in the elimination of $\beta-\mathrm{HCH}$ (as well as other isomers) ${ }^{14}$ despite the larger stability of the $1,3,5$-isomer. Such a result was attributed in a study on $\gamma-\mathrm{HCH}$ (lindane) dehydrochlorination to the occurrence of two conformers of rel$(3 R, 4 S, 5 S, 6 R)-1,3,4,5,6$-pentachlorocyclohexene (a diastereomer of $\mathbf{1})$ as the first reaction intermediate, leading to two different regioisomers of tetrachlorocyclohexa-1,4-diene, which finally afford 1,2,3- and 1,3,5- or, preferentially, $1,2,4-\mathrm{TCB}^{32}$. In contrast, our study on $\beta-\mathrm{HCH}$ elimination allows attributing the overall reaction selectivity to the higher acidity of a $\mathrm{CH}$ allylic group of the first reaction intermediate $\mathbf{1}$ which leads to the preferential formation of 7 (inexorably yielding 1,2,4-TCB).

\section{Conclusion}

In this theoretical study, the full mechanism on the $\beta-\mathrm{HCH}$ elimination reaction by hydroxide anion has been firstly reported. Results allow obtaining an insight into the three-stage reaction mechanism. The first stage involves the $\mathrm{E} 2$ elimination of $\beta-\mathrm{HCH}$ to yield 1. Although several pathways are possible for the subsequent $\mathbf{1}$ elimination in the second stage, the preferred path shows the proton removal from C6 (allylic carbon next to the chlorine-bearing vinylic carbon) to yield 7 . The subsequent elimination from 7 in the third stage can only yield $1,2,4-$ TCB. These results allow explaining experimental data showing that the rate-determining step corresponds to the first stage as well as the preferential formation of 1,2,4-TCB. We think that this new detailed insight on the reaction mechanism of the $\beta-\mathrm{HCH}$ dehydrochlorination reaction can be helpful in the rational design of the treatment for $\mathrm{HCH}$ waste stockpiles (e. g., involving a specific $\beta-\mathrm{HCH}$ treatment after separation by precipitation) $)^{33}$.

Computational methods. Calculations were carried out by using the Gaussian 09 package (version A.02) ${ }^{34}$. The activation barrier for the first stage (rate-controlling step) was studied by using Hartree-Fock ${ }^{35}$, $\mathrm{BLYP}^{36,37}, \mathrm{~B}^{2} \mathrm{LYP}^{36-38}$, and $\mathrm{M} 06-2 \mathrm{X}^{39}$ theoretical levels with the 6-311++G(d,p) basis set for all atoms through gas-phase as well as IEFPCM and CPCM (both involving water as an implicit solvent) media models. Instead, the full reaction mechanism (including all plausible conformations) was studied by means of the M06-2X functional since M06-2X/6-311++G(d,p) calculations had been successfully applied to some related studies, such as halogenated cyclohexanes ${ }^{40}$, cyclohexane puckering ${ }^{41}$ and E2 elimination (both anti and syn) reaction ${ }^{42}$. Calculations were studied through CPCM media model. All energy minima were identified by the lack of imaginary analytical frequencies, whereas all TSs were characterized by the occurrence of one imaginary frequency as well as Intrinsic Reaction Coordinate calculations linking the structures with the expected energy minima. 1,3-Dichlorocyclohex-2-en-1-yl anion was studied by means of Natural Bond Orbital (NBO) Analysis ${ }^{43}$ as implemented in Gaussian09. Hard data are gathered in the Electronic Supplementary Information.

Received: 17 February 2021; Accepted: 1 April 2021

Published online: 22 April 2021

\section{References}

1. Vijgen, J. et al. The legacy of pesticides and POPs stockpiles-a threat to health and the environment. Environ. Sci. Pollut. Res. 25(32), 31793-31798. https://doi.org/10.1007/s11356-018-3188-3 (2018).

2. Tripathi, V. et al. Restoring HCHs polluted land as one of the priority activities during the UN-International Decade on Ecosystem Restoration (2021-2030): A call for global action. Sci. Total Environ. 689, 1304-1315. https://doi.org/10.1016/j.scitotenv.2019.06. 444 (2019).

3. Vijgen, J. et al. HCH and lindane contaminated sites: European and global need for a permanent solution for a long-time neglected issue. Environ. Pollut. 248, 696-705. https://doi.org/10.1016/j.envpol.2019.02.029 (2019).

4. Vijgen, J. et al. Hexachlorocyclohexane (HCH) as new Stockholm Convention POPs-a global perspective on the management of lindane and its waste isomers. Environ. Sci. Pollut. Res. 18(2), 152-162. https://doi.org/10.1007/s11356-010-0417-9 (2011).

5. Cristol, S. J. et al. Mechanisms of elimination reactions. III. The kinetics of the alkaline dehydrochlorination of the benzene hexachloride isomers. II. J. Am. Chem. Soc. 73(2), 674-679. https://doi.org/10.1021/ja01146a050 (1951).

6. Li, S. et al. Hexachlorocyclohexanes in the environment: Mechanisms of dechlorination. Environ. Sci. Technol. 41(19), 1747-1792. https://doi.org/10.1080/10643389.2010.481592 (2011).

7. Ngabe, B. et al. Base hydrolysis of $\alpha$ - and $\gamma$-hexachlorocyclohexanes. Environ. Sci. Technol. 27(9), 1930-1933. https://doi.org/10. 1021/es00046a024 (1993).

8. Manna, R. N. et al. Dehydrochlorination of hexachlorocyclohexanes catalyzed by the LinA dehydrohalogenase. A QM/MM Study. J. Phys. Chem. B 119(49), 15100-15109. https://doi.org/10.1021/acs.jpcb.5b07538 (2015).

9. Shrivastava, N. et al. Novel LinA type $3 \delta$-hexachlorocyclohexane dehydrochlorinase. Appl. Environ. Microbiol. 81(21), 7553-7559. https://doi.org/10.1128/AEM.01683-15 (2015).

10. Wöhrnschimmel, H. et al. Comparative assessment of the global fate of $\alpha$ - and $\beta$-hexachlorocyclohexane before and after phaseout. Environ. Sci. Technol. 46(4), 2047-2054. https://doi.org/10.1021/es203109q (2012).

11. Abraham, M. et al. Hexachlorocyclohexane-Long term variability and spatial distribution in the Baltic Sea. Chemosphere 168, 1356-1364. https://doi.org/10.1016/j.chemosphere.2016.11.123 (2017). 
12. Willett, K. L. et al. Differential toxicity and environmental fates of hexachlorocyclohexane isomers. Environ. Sci. Technol. 32(15), 2197-2207. https://doi.org/10.1021/es9708530 (1998).

13. Nayyar, N. et al. Hexachlorocyclohexane: Persistence, toxicity and decontamination. Rev. Environ. Health 29(1-2), 49-52. https:// doi.org/10.1515/reveh-2014-0015 (2014).

14. Hughes, E. D. et al. Mechanism of elimination reactions. Part. XVIII Kinetics and steric course of elimination from isomeric benzene hexachlorides. J. Chem. Soc. https://doi.org/10.1039/JR9530003832 (1953).

15. Yan, H. et al. Standard enthalpies of formation and enthalpies of isomerization of trichlorobenzenes. Huaxue Xuebao 45(12), 1184-1187 (1987).

16. Guner, V. et al. A Standard set of pericyclic reactions of hydrocarbons for the benchmarking of computational methods: the performance of $a b$ Initio, Density Functional, CASSCF, CASPT2, and CBS-QB3 methods for the prediction of activation barriers, reaction energetics, and transition state geometries. J. Phys. Chem. A 107(51), 11445-11449. https://doi.org/10.1021/jp035501w (2003).

17. Baker, J. \& Pulay, P. Assessment of the Handy-Cohen optimized exchange density functional for organic reactions. J. Chem. Phys. 117(4), 1441-1449. https://doi.org/10.1063/1.1485723 (2002).

18. Lan, Y. et al. Computational methods to calculate accurate activation and reaction energies of 1,3-dipolar cycloadditions of 24 1,3-dipoles. J. Phys. Chem. A 115(47), 13906-13920. https://doi.org/10.1021/jp207563h (2011).

19. Satptathy, L. et al. Solvent effect on the potential energy surfaces of the $\mathrm{F}^{-}+\mathrm{CH}_{3} \mathrm{CH}_{2} \mathrm{Br}$ reaction. J. Phys. Chem. A 122(27), 5861-5869. https://doi.org/10.1021/acs.jpca.8b02687 (2018).

20. Klamt, A. et al. A comprehensive comparison of the IEFPCM and SS(V)PE method with the COSMO approach. J. Chem. Theory Comput. 11(9), 4220-4225. https://doi.org/10.1021/acs.jctc.5b00601 (2015).

21. Hine, J. et al. The mechanism of the dehydrochlorination of $\beta$-benzene hexachloride. J. Am. Chem. Soc. 88(23), 5522-5525. https:// doi.org/10.1021/ja00975a030 (1966).

22. Bachrach, S. M. organic reactions of anions. In Computational Organic Chemistry, 2nd ed. 373-443 (Wiley-Blackwell, 2014). https://doi.org/10.1002/9780470148136.ch5

23. Milenković, D. A. et al. Advanced oxidation process of coumarins by hydroxyl radical: Towards the new mechanism leading to less toxic products. Chem. Eng. J. 395, 124971. https://doi.org/10.1016/j.cej.2020.124971 (2020).

24. Dahlke, G. D. \& Kass, S. R. Substituent effects in the gas phase: 1-substituted allyl anions. J. Am. Chem. Soc. 113(15), 5566-5573. https://doi.org/10.1021/ja00015a008 (1991).

25. Bent, H. A. An appraisal of valence-bond structures and hybridization in compounds of the first-row elements. Chem. Rev. 61(3), 275-311. https://doi.org/10.1021/cr60211a005 (1961).

26. Ghosh, D. C. et al. Density functional and molecular orbital study of physical process of inversion of nitrogen trifluoride $\left(\mathrm{NF}_{3}\right)$ molecule. Int. J. Quantum Chem. 87(3), 111-134. https://doi.org/10.1002/qua.10087 (2002).

27. Li, Z. et al. Variations in rotational barriers of allyl and benzyl cations, anions, and radicals. J. Org. Chem. 81(20), 9576-9584. https://doi.org/10.1021/acs.joc.6b01530 (2016).

28. Bartmess, J. E. \& Burnham, R. D. Effect of central substituents on the gas-phase acidities of propenes. J. Org. Chem. 49(8), 1382-1387. https://doi.org/10.1021/jo00182a013 (1984).

29. Fernández, J. et al. POP-contaminated sites from HCH production in Sabiñánigo, Spain. Environ. Sci. Pollut. Res. 20(4), 1937-1950. https://doi.org/10.1007/s11356-012-1433-8 (2013).

30. Bickelhaupt, F. M. et al. Theoretical investigation on base-induced 1,2-eliminations in the model system fluoride ion + fluoroethane. The role of the base as a catalyst. J. Am. Chem. Soc. 115(20), 9160-9173. https://doi.org/10.1021/ja00073a035 (1993).

31. Yang, L. et al. Competing E2 and $\mathrm{S}_{\mathrm{N}} 2$ mechanisms for the $\mathrm{F}^{-}+\mathrm{CH}_{3} \mathrm{CH}_{2} \mathrm{I}$ reaction. J. Phys. Chem. A 121(5), 1078-1085. https://doi. org/10.1021/acs.jpca.6b09546 (2017).

32. Zinovyev, S. S. et al. Dechlorination of lindane in the multiphase catalytic reduction system with $\mathrm{Pd} / \mathrm{C}, \mathrm{Pt} / \mathrm{C}$ and Raney-Ni. Appl. Catal. B 47(1), 27-36. https://doi.org/10.1016/S0926-3373(03)00324-2 (2004).

33. Xiao, H. et al. Compilation, evaluation, and selection of physical-chemical property data for $\alpha$-, $\beta$-, and $\gamma$-hexachlorocyclohexane. J. Chem. Eng. Data 49(2), 173-185. https://doi.org/10.1021/je034214i (2004).

34. Frisch, M. J. et al. Gaussian 09, Revision A02 (Gaussian Inc, Wallingford, CT, 2009).

35. Roothaan, C. C. J. New developments in molecular orbital theory. Rev. Mod. Phys. 23(2), 69-89. https://doi.org/10.1103/RevMo dPhys.23.69 (1951).

36. Becke, A. D. Density-functional exchange-energy approximation with correct asymptotic-behavior. Phys. Rev. A 38(6), 3098-3100. https://doi.org/10.1103/PhysRevA.38.3098 (1988).

37. Lee, C. et al. Development of the Colle-Salvetti correlation-energy formula into a functional of the electron density. Phys. Rev. B 37(2), 785-789. https://doi.org/10.1103/PhysRevB.37.785 (1988).

38. Becke, A. D. 1993 Density-functional thermochemistry. III. The role of exact exchange. J. Chem. Phys. 98(7), 5648-5652. https:// doi.org/10.1063/1.464913 (1993).

39. Zhao, Y. \& Truhlar, D. G. Density functionals with broad applicability in Chemistry. Acc. Chem. Res. 41(2), 157-167. https://doi. org/10.1021/ar700111a (2008).

40. Umadevi, V. et al. Understanding molecular properties of halogenated cyclohexane-A DFT study. Comput. Theor. Chem. 1049, 55-61. https://doi.org/10.1016/j.comptc.2014.09.019 (2014).

41. Kang, Y. K. \& Park, H. S. Puckering transitions in cyclohexane: Revisited. Chem. Phys. Lett. 702, 82-89. https://doi.org/10.1016/j. cplett.2018.05.004 (2018).

42. Zhao, Y. \& Truhlar, D. G. Density functional calculations of $\mathrm{E} 2$ and $\mathrm{S}_{\mathrm{N}} 2$ reactions: Effects of the choice of density functional, basis set, and self-consistent iterations. J. Chem. Theory Comput. 6(4), 1104-1108. https://doi.org/10.1021/ct100082z (2010).

43. Glendening, E. D. et al. NBO Version 3.1

44. Legault, C. Y. CYLView, 1.0b, Université de Sherbrooke (2009). http://www.cylview.org

\section{Acknowledgements}

We are indebted to the Instituto de Síntesis Química y Catálisis Homogénea (ISQCH) and the Instituto de Biocomputación y Física de Sistemas Complejos (BIFI) for allocation of computer time. We also thank financial support from the Ministerio de Ciencia, Innovación y Universidades (project RTI2018-093431-B-I00), the Gobierno de Aragón (reference research group E37_20R; Order of the Regional Minister of Rural Development and Sustainability of 27 March 2018, extended) and European Regional Development Fund (Feder 2014-2020, "Construyendo Europa desde Aragón"). Z. H. expresses his gratitude to the Gobierno de Aragón and the European Social Fund for a PhD grant.

\section{Author contributions}

A.B. and Z.H. performed the theoretical calculations. L.S. supervised the work and wrote the manuscript draft. All authors participated in the scientific discussion and validated the manuscript. 


\section{Competing interests}

The authors declare no competing interests.

\section{Additional information}

Supplementary Information The online version contains supplementary material available at https://doi.org/ 10.1038/s41598-021-88060-7.

Correspondence and requests for materials should be addressed to L.S.

Reprints and permissions information is available at www.nature.com/reprints.

Publisher's note Springer Nature remains neutral with regard to jurisdictional claims in published maps and institutional affiliations.

(c) (1) Open Access This article is licensed under a Creative Commons Attribution 4.0 International License, which permits use, sharing, adaptation, distribution and reproduction in any medium or format, as long as you give appropriate credit to the original author(s) and the source, provide a link to the Creative Commons licence, and indicate if changes were made. The images or other third party material in this article are included in the article's Creative Commons licence, unless indicated otherwise in a credit line to the material. If material is not included in the article's Creative Commons licence and your intended use is not permitted by statutory regulation or exceeds the permitted use, you will need to obtain permission directly from the copyright holder. To view a copy of this licence, visit http://creativecommons.org/licenses/by/4.0/.

(C) The Author(s) 2021 